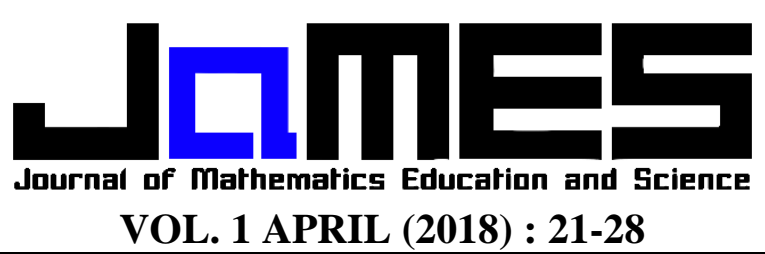

p-ISSN: 2621-1203

e-ISSN: 2621-1211

\title{
PERLUASAN SIFAT RANK MATRIKS BUJURSANGKAR ATAS RING KOMUTATIF DITINJAU DARI DETERMINANNYA
}

\author{
Ismanto ${ }^{1}$ \\ Universitas Nahdlatul Ulama Sunan Giri, ismanto0910@ unugiri.ac.id $^{1}$ \\ Received : 21 Maret 2018, Accepted : 1 April 2018, @ Mathematics Education Unugiri 2018
}

\begin{abstract}
This paper is described the properties rank of square matrices over commutative ring if connected with it's determinant. Rank of $\mathrm{n} \times \mathrm{n}$ matrix over commutative ring is less than $\mathrm{n}$, if it's determinant is an element of zero divisor in R.Rank of $\mathrm{n} x \mathrm{n}$ matrix over commutative ring is $\mathrm{n}$, if it's determinant is not element of zero divisor in $\mathrm{R}$.
\end{abstract}

Keywords: ideal, annihilator, rank of matrices over commutative ring

\begin{abstract}
Abstrak
Makalah ini membahas sifat-sifat rank matriks bujursangkar atas ring komutatif jika dihubungkan dengan determinannya. Rank matriks atas ring komutatif ukuran $n \times n$ lebih kecil dari $n$, jika determinannya merupakan anggota pembagi nol di $R$.Rank matriks atas ring komutatif ukuran $n \times n$ sama dengan $n$,jika determinannya bukan anggota pembagi nol di $R$.
\end{abstract}

Kata kunci: ideal, annihilator, rank matriks atas ring komutatif

\section{Pendahuluan}

Matriks atas ring komutatif adalah matriks yang semua entrinya merupakan anggota ring komutatif. Salah satu konsep penting dalam matriks atas ring komutatif adalah rank. Rank matriks atas ring komutatif merupakan konsep yang mendasari teoremateorema penting dalam pembahasan matriks atas ring komutatif. Misalnya, untuk membuktikan eksistensi pembagi nol pada matriks bujursangkar atas ring komutatif. Selain itu, konsep rank juga diperlukan untuk membangun suatu matriks pembagi nol pada matriks atas ring komutatif.

Pembahasan keterkaitan sifat rank matriks atas ring komutatif dengan determinannya masih sangat terbatas. Berbagai literatur memfokuskan pembahasan rank matriks atas ring komutatif dimana determinannya merupakan anggota pembagi nol di ring komutatif. Pada makalah ini, selain dibahas sifat rank matriks atas ring komutatif dimana determinannya merupakan anggota pembagi nol pada ring komutatif, tetapi juga dibahas sifat rank matriks atas ring komutatif jika determinannya bukan anggota pembagi nol pada ring komutatif.

Makalah ini bertujuan untuk membuktikan berbagai sifat rank matriks atas ring komutatif dimana determinannya merupakan anggota pembagi nol pada ring komutatif. Selain itu, juga akan dibahas rank matriks atas ring komutatif dimana determinannya bukan anggota pembagi nol di ring komutatif. Misalnya, bagaimana rank matriks atas ring komutatif jika determinan matriksnya anggota unit di ring komutatif atau bagaimana rank matriks atas ring komutatif jika determinan matriksnya bukan pembagi nol di ring komutatif. Dengan demikian, makalah ini diharapkan dapat memperluas sifat-sifat rank matriks atas ring komutatif. 


\section{Dasar Teori}

Berikut diberikan beberapa definisi penting tentang himpunan. Konsep himpunan yang dibahas adalah definisi tentang himpunan bagian dan definisi tentang kesamaan dua himpunan

\section{Definisi 2.1. Himpunan Bagian [1]}

Himpuan $A$ disebut subset (himpunan bagian) dari himpunan $B$ jika setiap elemen $A$ merupakan elemen $B$. Dengan kata lain, $A \subseteq$ $B$ jika $x \in A$ maka $x \in B$.

Definisi 2.2. Kesamaan Dua Himpunan [1] Diberikan dua himpunan tak kosong $A$ dan $B . A$ dikatakan sama dengan $B$ dinotasikan $A=B$ jika $A \subseteq B$ dan $B \subseteq A$.

Operasi biner dibentuk dari pemetaan. Pembahasan tentang operasi biner diperlukan karena operasi biner merupakan bagian tidak terpisahkan ketika membahas struktur aljabar. Berikut dibahas pengertian pemetaan, operasi biner, dan sifat-sifat operasi biner

\section{Definisi 2.3. Pemetaan [1]}

Diberikan dua himpunan $A$ dan $B$. Relasi $f: A \rightarrow$ $B$ dikatakan pemetaan dari $A$ ke $B$ jika setiap $a \in A$ mempunyai tepat satu kawan di $B$.

\section{Definisi 2.4. Operasi Biner [1]}

Diberikan himpunan tak kosong $S$ dan sebuah pemetaan $*: S x S \rightarrow S$, * dinamakan operasi biner di himpunan $S$ yang memetakan setiap pasangan $(x, y) \in S x S$ ke $x * y \in S$

\section{Teorema 2.1. Sifat operasi biner [1]}

Operasi biner $*: S x S \rightarrow S$ pada himpunan $S$ adalah:

a. komutatif jika $x * y=y * x$, untuk setiap $x, y \in S$

b. asosiatif jika $x *(y * z)=(x * y) * z$, untuk setiap $x, y, z \in S$

c. jika $\circ$ adalah operasi biner lain di $S$, maka * distribusi kiri atas $\circ$ jika $x *(y \circ z)=$ $(x * y) \circ(x * z)$, untuk semua $x, y, z \in S$

d. jika $\bigcirc$ adalah operasi biner lain di $S$, maka $*$ distribusi kanan atas $\circ$ jika $(y \circ z) * x=$ $(y * x) \circ(z * x)$, untuk semua $x, y, z \in S$

e. jika * distribusi kiri sekaligus kanan atas $\bigcirc$, maka $*$ disebut distributif atas $\circ$

Berikut ini diberikan definisi-definisi dasar dalam aljabar abstrak. Definisi tersebut meliputi definisi tentang grup, ring, pembagi nol di ring, unit di ring, ideal di ring.

\section{Definisi 2.5. Grup [1]}

Diberikan himpunan tak kosong $G$ dengan sebuah operasi biner * pada $G$ ditulis $\left(G,^{*}\right)$ disebut grup jika aksioma berikut dipenuhi:

a. asosiatif yaitu $a *(b * c)=(a * b) * c$, unruk setiap $a, b, c \in G$

b. ada elemen identitas $e \in G$ sehingga $e * a=$ $a * e=a$, untuk sebarang $a \in G$

c. setiap $a \in G$ mempunyai invers yaitu $a^{-1} \in$ $G$ sehingga $a * a^{-1}=a^{-1} * a=e$

\section{Definisi 2.6. Grup Abelian [1]}

Suatu grup $(G, *)$ disebut grup abelian (atau komutatif) jika $a * b=b * a$, untuk setiap $a, b \in G$

\section{Definisi 2.7. Ring [3]}

Ring $R$ adalah himpunan yang disertai dua operasi biner yaitu + dan $\cdot$ disebut operasi penjumlahan dan pergandaan yang memenuhi aksioma berikut:

a. $(R,+)$ adalah grup abelian

b. $(R, \bullet)$ tertutup dan berlaku hukum asosiatif

c. Berlaku hukum distributif yaitu untuk semua $a, b, c \in R$, berlaku

$$
\begin{aligned}
& a \cdot(b+c)=a \cdot b+a \cdot c \text { dan } \\
& (a+b) \cdot c=a \cdot c+b \cdot c
\end{aligned}
$$

Ring $R$ disebut ring komutatif jika terhadap operasi pergandaan mmenuhi hukum komutatif, dan ring $R$ dikatakan mempunyai elemen satuan (mengandung 1) jika terdapat $1 \in R$ sehingga $1 . a=a .1=a$ untuk sebarang $a \in R$

\section{Definisi 2.8. Pembagi Nol di R [2]}

Jika $R$ sebuah ring, $R \neq \varnothing$, maka $R$ minimal terdiri dari dua elemen. Diberikan $R^{*}=R-$ $\{0\}$ adalah elemen-elemen tak nol di $R$. Suatu 
$x \in R$ dikatakan pembagi nol kiri di $R$ jika $x y=$ 0 , untuk $y \in R^{*}$. Begitu juga $x \in R$ dikatakan pembagi nol kanan di $R$ jika $y x=0$, untuk $y \in$ $R^{*}$. Himpunan semua pembagi nol di $R$ dinotasikan $Z(R)$. Jika $x \in Z(R)$, maka $x$ adalah pembagi nol kanan atau pembagi nol kiri di $R$.

\section{Definisi 2.9. Unit di R [2]}

Elemen $x$ di ring $R$ disebut unit jika $x y=y x=$ 1 , untuk $y \in R$. Himpunan semua unit di ring $R$ dinotasikan $U(R)$.

\section{Definisi 2.10. Ideal di R [1]}

Himpunan tak kosong $S$ subset dari ring $R$ dinamakan ideal jika:

a. $a, b \in S$ maka $a-b \in S$

b. $a \in S$ dan $r \in R$ maka $a r \in S$ dan $r a \in S$.

Matriks atas ring komutatif adalah matriks yang semua entrinya merupakan anggota dari ring komutatif. Berikut ini diberikan definisi tentang matriks atas ring komutatif, sifat entrinya dan transpos matriks atas ring komutatif.

\section{Definisi 2.11. Pengertian Matriks Atas Ring Komutatif [2]}

Himpunan semua matriks $m x n$ dengan entrientrinya dari ring komutatif $R$ diberi notasi $M_{m x n}(R)$. Jika $A \in M_{m x n}(R)$ maka $A$ dapat ditulis

$$
A=\left[\begin{array}{ccc}
a_{11} & \cdots & a_{1 n} \\
\vdots & \ddots & \vdots \\
a_{m 1} & \cdots & a_{m n}
\end{array}\right] \in M_{m x n}(R)
$$

dimana $a_{i j} \in R$ dengan $i=1, \ldots, m$ dan $j=$ $1, \ldots, n$

Definisi 2.12. Sifat Entri $\boldsymbol{M}_{\boldsymbol{m x n}}(\boldsymbol{R})$ [2] Jika $A \in M_{m x n}(R)$, maka $[A]_{i j}$ adalah elemen ke- $i j$ dari matrik $A$ yaitu

$A=\left[\begin{array}{ccc}a_{11} & \cdots & a_{1 n} \\ \vdots & \ddots & \vdots \\ a_{m 1} & \cdots & a_{m n}\end{array}\right]=\left[\begin{array}{ccc}{[A]_{11}} & \cdots & {[A]_{1 n}} \\ \vdots & \ddots & \vdots \\ {[A]_{m 1}} & \cdots & {[A]_{m n}}\end{array}\right]$ dimana $a_{i j}=[A]_{i j}$ untuk $i=1, \ldots, m$ dan $j=$ $1, \ldots, n$. Diberikan $A, B \in M_{m x n}(R)$ dan $r \in R$, maka $A+B$ adalah matriks $m x n$ yang elemennya adalah $[A+B]_{i j}=[A]_{i j}+[B]_{i j}$ dan $r A$ juga matriks $m x n$ yang elemennya adalah $[r A]_{i j}=r[A]_{i j}$ untuk $i=1, \ldots, m$ dan $j=1, \ldots, n$.

\section{Definisi 2.13. Transpose Matriks $M_{m x n}(R)$} [1]

Diberikan $A=\left(a_{i j}\right) \in R$ adalah sebuah matriks $m \times n$. Transpos dari $A$ adalah matriks $B_{n x m}=$ $\left(b_{i j}\right)$ dimana $b_{i j}=a_{j i},(i, j) \in n \times m$

Determinan matriks atas ring komutatif merupakan konsep dasar dalampembahasan rank, karena determinan merupakan pembentuk ideal dari sebarang matriks atas ring komutatif. Berikut ini diberikan definisi tentang minor $M_{m x n}(R)$, kofaktor $M_{m x n}(R)$ beserta teorema tentang determinan transpos matriks atas ring komutatif.

Definisi 2.14. Minor $M_{m x n}(R)$ [2]

Diberikan ,dan $1 \leq t \leq \min \{m, n\}$ maka $\Delta\left(i_{1}, \ldots, i_{t}: j_{1}, \ldots, j_{t}\right)$ adalah minor dari matriks $A$ dimana baris yang digunakan $i_{1}, \ldots, i_{t}$ dan kolom yang digunakan $j_{1}, \ldots, j_{t}$ dimana $1 \leq$ $i_{1}<\cdots<i_{t} \leq m$ dan $1 \leq j_{1}<\cdots<j_{t} \leq m$

\section{Definisi 2.15. Minor dan Kofaktor $M_{m x n}(R)$ [2]}

Diberikan $A \in M_{m \times n}(R)$,

a. Untuk $i, j=1, \ldots, n, M_{i j}$ adalah $(n-$ 1) $x(n-1)$ minor $A$ yaitu menghapus baris ke- $i$ dan kolom ke- $j$

b. Elemen $(-1)^{i+j} M_{i j}$ disebut kofaktor ke-ij dari A dan ditulis $\operatorname{Cof}_{i j}(A)$. Jadi $\operatorname{Cof}_{i j}(A)=$ $(-1)^{i+j} \Delta(1, \ldots, \hat{\imath}, \ldots, n ; 1, \ldots, \hat{\jmath}, \ldots, n)$

dimana $\hat{\imath}$ dan $\hat{\jmath}$ adalah baris ke- $i$ dan kolom ke-j yang dihapus

\section{Definisi 2.16. Detereminan Matriks $A \in$} $M_{m x n}(R)$ [4]

Determinan matriks $A \in M_{m x n}(R)$, diberi notasi $\operatorname{det}(A)$ adalah skalar dengan definisi sebagai berikut:

a. $\operatorname{det}(A)=a_{11}$, untuk $n=1$

b. $\operatorname{det}(A)=a_{11} \operatorname{Cof}_{11}(A)+\ldots+$

$a_{1 n} \operatorname{Cof}_{1 n}(A)$, untuk $n>1$, dimana 
$\operatorname{Cof} f_{1 j}(A)$ adalah ekspansi kofaktor atas baris pertama matriks $A$ untuk $j=1, \ldots, n$

Teorema 2.2. Determinan Transpose Matriks $\boldsymbol{M}_{m x n}(R)$ [2]

Jika $A \in M_{n x n}(R)$, maka $\operatorname{det}\left(A^{t}\right)=\operatorname{det}(A)$ untuk $A^{t}$ adalah transpos dari matriks $A$.

\section{Bukti:}

Untuk matriks $A \in M_{n x n}(R)$ yang diberikan. Menurut Definisi 2.16, $\operatorname{det}(A)$ dapat diekspresikan sebagai ekspansi kofaktor $A$ atas baris ke- $i$ dari matriks $A$, yaitu

$\operatorname{det}(A)=a_{i 1} \operatorname{Cof}_{i 1}(A)+\ldots+a_{i n} \operatorname{Cof}_{1 n}(A)$

Diberikan matriks $B$, menurut Definisi 2.16, diperoleh ekspansi kofaktor $B$ atas kolom ke- $i$ dari $B$ yaitu $\operatorname{det}(B)=b_{1 i} \operatorname{Cof}_{1 i}(B)+\ldots+$ $b_{n i} \operatorname{Cof}_{n i}(B)$. Untuk $\quad[A]_{i j}=[B]_{j i}$ mengakibatkan $\operatorname{Cof}_{i j}(A)=\operatorname{Cof}_{j i}(B)$, untuk $j=1, \ldots, n$. Oleh karena itu,

$$
\begin{aligned}
\operatorname{det}(A) & =a_{i 1} \operatorname{Cof}_{i 1}(A)+\ldots+a_{i n} \operatorname{Cof}_{1 n}(A) \\
& =b_{1 i} \operatorname{Cof}_{1 i}(B)+\ldots+b_{n i} \operatorname{Cof}_{n i}(B) \\
& =\operatorname{det}(B) \\
& =\operatorname{det}\left(A^{t}\right)
\end{aligned}
$$

Rank matriks $M_{m x n}(R)$ dibentuk oleh ideal $R$ yang dibangun dari semua minor $M_{m x n}(R)$ dan annihilator ideal-ideal tersebut. Berikut diberikan definisi ideal $R$ dari semua minor $M_{m \times n}(R)$, annihilator dan rank matriks $M_{m \times n}(R)$.

\section{Definisi 2.17. Ideal $\mathrm{R}$ dari $\operatorname{Minor} M_{m x n}(R)$ [2]}

Diberikan $A \in M_{m x n}(R)$, untuk $t=$ $1, \ldots, r=\min \{m, n\}, I_{t}(A)$ adalah ideal $R$ yang dibangun oleh semua minor txt dari matriks $A \in M_{m \times n}(R)$.

\section{Definisi 2.18. Annihilator [2]}

Diberikan $M=R-$ Module

a. untuk $m \in M, A n n_{R}(m)=$ $\{x \in R \mid x m=0\}$

b. dan $A n n_{R}(M)=$ $\{x \in R \mid x m=0$, untuk $\forall m \in M\}$

Definisi 2.19. Rank Matriks $M_{m x n}(R)$ [2] Diberikan $A \in M_{m x n}(R)$, rank $A$ ditulis $r k(A)$ yaitu $r k(A)=\operatorname{maks}\left\{t \mid \operatorname{Ann}_{R}\left(I_{t}(A)\right)=(0)\right\}$

\section{Hasil dan Pembahasan}

Rank matriks atas ring komutatif $A \in$ $M_{m x n}(R)$ yang dinotasikan $r k(A)$ dapat ditentukan dengan cara menentukan nilai annihilator dari semua ideal yang dibangun dari semua minor-minor yang dapat dibangun dari matriks $A$. Selanjutnya ditentukan nilai maksimum dari $t \in Z$ dimana annihilator semua ideal-idealnya sama dengan 0 . Oleh karena itu, sebelum membahas lebih lanjut tentang rank matriks atas ring komutatif, dibahas terlebih dahulu teorema tentang rangkaian naik ideal $R$ yang dibangun minor matriks $A \in M_{m x n}(R)$ dan akibat dari teorema tersebut.

Berdasarkan Definisi 2.17, diperoleh bahwa anggota dari ideal di $R$ yang dibangun oleh semua minor $t x t$ dari matriks $A \in$ $M_{m \times n}(R)$ yang dinotasikan $I_{t}(A)$ adalah kombinasi linier dari seluruh minor $t x t$ matriks $A \in M_{m x n}(R)$. Berikut ini dibahas Teorema 3.1 tentang rangkaian naik ideal di $R$ yang dibangun minor-minor matriks $A \in M_{m x n}(R)$ beserta akibatnya.

\section{Teorema 3.1. Rangkaian Naik Ideal $I_{t}(A)$ di} $R$ [2]

Diketahui $A \in M_{m x n}(R)$ dan $t=1, \ldots, r=$ $\min \{m, n\} . \quad I_{t}(A)$ adalah ideal di $R$ yang dibangun oleh semua minor $t x t$ dari matriks $A \in M_{m \times n}(R)$.

$I_{r}(A) \subseteq I_{r-1}(A) \subseteq \cdots \subseteq I_{2}(A) \subseteq I_{1}(A) \subseteq R$ merupakan rangkaian naik ideal di $R$.

\section{Bukti:}

Menurut Definisi 2.1, untuk membuktikan $I_{t}(A) \subseteq I_{t-1}(A) \quad$ dimana $\quad t=1, \ldots, r=$ $\min \{m, n\}$, ambil sebarang $x \in I_{t}(A)$ dan ditunjukkan $x \in I_{t-1}(A)$. Misal untuk sebarang matriks $A \in M_{m \times n}(R)$, ambil submatriks $t \times t$ dimana $t=1, \ldots, r=\min \{m, n\}$ yaitu

$$
S_{t}(A)=\left(\begin{array}{ccc}
a_{i_{1} j_{1}} & \cdots & a_{i_{1} j_{t}} \\
\vdots & \ddots & \vdots \\
a_{i_{t} j_{1}} & \cdots & a_{i_{t} j_{t}}
\end{array}\right)
$$

Menurut Definisi 2.14 minor dari $S_{t}(A)$ adalah $\Delta\left(i_{1}, \ldots, i_{t} ; j_{1}, \ldots, j_{t}\right)=\operatorname{det}\left(\begin{array}{ccc}a_{i_{1} j_{1}} & \cdots & a_{i_{1} j_{t}} \\ \vdots & \ddots & \vdots \\ a_{i_{t} j_{1}} & \cdots & a_{i_{t} j_{t}}\end{array}\right)$ 
Sehingga diperoleh $\Delta\left(i_{1}, \ldots, i_{t} ; j_{1}, \ldots, j_{t}\right)=$ $\left|S_{t}(A)\right|$. Ambil sebarang anggota $I_{t}(A)$ misalkan $\quad \Delta\left(i_{1}, \ldots, i_{t} ; j_{1}, \ldots, j_{t}\right) R=\left|S_{t}(A)\right| R$. Menurut Definisi $2.16 \Delta\left(i_{1}, \ldots, i_{t} ; j_{1}, \ldots, j_{t}\right)$ dapat diekspresikan sebagai ekspansi kofaktor $S_{t}(A)$ atas baris terakhirnya sehingga diperoleh

$$
\begin{aligned}
\Delta\left(i_{1}, \ldots, i_{t} ; j_{1}, \ldots, j_{t}\right) & \\
& =a_{i_{t} j_{1}} \operatorname{Cof}_{i_{t} j_{1}}\left(S_{t}(A)\right)+\ldots \\
& +a_{i_{t} j_{t}} \operatorname{Cof}_{i_{t} j_{t}}\left(S_{t}(A)\right) \\
& =\sum_{s=1}^{t} a_{i_{t} j_{s}} \operatorname{Cof}_{i_{t} j_{s}}\left(S_{t}(A)\right)
\end{aligned}
$$

Menurut Definisi $2.15 \mathrm{~b}$, untuk $s=1, \ldots, t$ dan $k=i_{t}+j_{s}$ berlaku

$$
\operatorname{Cof}_{i_{t} j_{s}}\left(S_{t}(A)\right)=(-1)^{k} M_{i_{t} j_{s}}\left(S_{t}(A)\right) \text {. }
$$

Karena menurut Definisi 2.15.a $M_{i_{t} j_{s}}\left(S_{t}(A)\right)$ adalah minor $S_{t}(A)$ dengan menghapus baris ke- $i_{t}$ dan kolom ke- $j_{s}$ sehingga diperoleh bahwa $\Delta\left(i_{1}, \ldots, i_{t} ; j_{1}, \ldots, j_{t}\right) R=\left|S_{t}(A)\right| R \in I_{t-1}(A)$.

Dengan demikian diperoleh bahwa $I_{t}(A) \subseteq I_{t-1}(A)$. Karena $t=1, \ldots, r$ dimana $r=\min \{m, n\}$ terbukti bahwal $I_{r}(A) \subseteq$ $I_{r-1}(A) \subseteq \cdots \subseteq I_{2}(A) \subseteq I_{1}(A) \subseteq R$.

\section{Akibat Teorema 3.1.}

Rangkaian naik ideal di Teorema 3.1 dapat diperluas untuk $t \in Z$ sehingga diperoleh $I_{t}(A)=\left\{\begin{array}{c}(0), \text { jika } t>\min \{m, n\} \\ R, \text { jika } t \leq 0\end{array}, \quad\right.$ sehingga diperoleh rangkaian naik ideal di $R$ yaitu $(0)=I_{r+1}(A) \subseteq I_{r}(A) \subseteq I_{r-1}(A) \subseteq \cdots \subseteq$ $I_{1}(A) \subseteq I_{0}(A)=R$

\section{Contoh:}

Diketahui ring komutatif $R=Z_{6}=$ $\{\overline{0}, \overline{1}, \overline{\overline{2}}, \overline{3}, \overline{4}, \overline{5}\}$ dan matriks

$$
A=\left[\begin{array}{ll}
\overline{1} & \overline{2} \\
\overline{1} & \overline{4} \\
\overline{0} & \overline{2}
\end{array}\right] \in M_{3 x 2}(R) .
$$

Ditentukan $I_{t}(A)$ dimana $t=1,2$ yaitu $I_{1}(A)$ dan $I_{2}(A)$. Untuk menentukan $I_{1}(A)$, terlebih dahulu ditentukan semua submatriks 1 x 1 dari matriks $A$ yaitu $[\overline{0}],[\overline{1}],[\overline{2}]$ dan $[\overline{4}]$. Berdasarkan submatriks 1 x 1 yang terbentuk ditentukan determinan dari semua submatriks 1 x 1 tersebut. Menurut Definisi 2.16.a diperoleh $|\overline{0}|=\overline{0},|\overline{1}|=\overline{1},|\overline{2}|=\overline{2}$ dan $|\overline{4}|=\overline{4}$. Selanjutnya, ditentukan semua minor dari submatriks 1 x 1 dari $A$. Menurut Definisi 2.15 diperoleh

$\Delta(3 ; 1)=|\overline{0}|=\overline{0}, \quad \Delta(1 ; 1)=\Delta(2 ; 1)=|\overline{1}|=$ $\overline{1}, \Delta(1 ; 2)=\Delta(3 ; 2)=|\overline{2}|=\overline{2}$ dan $\Delta(2 ; 2)=$ $|\overline{4}|=\overline{4}$. Berdasarkan semua minor $1 \times 1$ dari $A$ diperoleh $I_{1}(A)$. Menurut Definisi 2.17. $I_{1}(A)=$ $\overline{0} R+\overline{1} R+\overline{2} R+\overline{4} R=R$. Diperoleh bahwa $I_{1}(A)=R$.

Untuk menentukan $I_{2}(A)$, terlebih dahulu ditentukan semua submatriks 2 × 2 yang dapat dibangun dari matriks $A$ yaitu

$$
\left[\begin{array}{ll}
\overline{1} & \overline{2} \\
\overline{1} & \overline{4}
\end{array}\right],\left[\begin{array}{ll}
\overline{1} & \overline{4} \\
\overline{0} & \overline{2}
\end{array}\right] \text { dan }\left[\begin{array}{ll}
\overline{1} & \overline{2} \\
\overline{0} & \overline{2}
\end{array}\right] \text {. }
$$

Berdasarkan submatriks 2 × 2 yang terbentuk ditentukan determinan dari semua submatriks 2 x 2 tersebut. Menurut Definisi 2.16.a diperoleh

$$
\left|\begin{array}{ll}
\overline{1} & \overline{2} \\
\overline{1} & \overline{4}
\end{array}\right|=\left|\begin{array}{ll}
\overline{1} & \overline{4} \\
\overline{0} & \overline{2}
\end{array}\right|=\left|\begin{array}{ll}
\overline{1} & \overline{2} \\
\overline{0} & \overline{2}
\end{array}\right|=\overline{2} .
$$

Selanjutnya, ditentukan semua minor dari submatriks 2 × 2 dari $A$, menurut Definisi 2.15 diperoleh

$$
\begin{aligned}
& \Delta(1,2 ; 1,2)=\left|\begin{array}{ll}
\overline{1} & \overline{2} \\
\overline{1} & \overline{4}
\end{array}\right|=\overline{2}, \\
& \Delta(2,3 ; 1,2)=\left|\begin{array}{ll}
\overline{1} & \overline{4} \\
\overline{0} & \overline{2}
\end{array}\right|=\overline{2} \text { dan } \\
& \Delta(1,3 ; 1,2)=\left|\begin{array}{ll}
\overline{1} & \overline{2} \\
\overline{0} & \overline{2}
\end{array}\right|=\overline{2} .
\end{aligned}
$$

Berdasarkan semua minor submatriks 2 × 2 dari matriks $A$ diperoleh $I_{2}(A)$. Menurut Definisi $2.17, I_{2}(A)=\overline{2} R=\{\overline{0}, \overline{2}, \overline{4}\}$. Diperoleh bahwa $I_{2}(A)=\{\overline{0}, \overline{2}, \overline{4}\}$

Karena $I_{1}(A)=R=\{\overline{0}, \overline{1}, \overline{\overline{2}}, \overline{3}, \overline{4}, \overline{5}\}$ dan $I_{2}(A)=\{\overline{0}, \overline{2}, \overline{4}\}$, menurut Definisi 2.2 terbukti bahwa $I_{2}(A) \subseteq I_{1}(A)$. Hal ini sesuai dengan Teorema 3.1.

Teorema 3.2. Sifat Rank Matriks $A \in$ $M_{m x n}(R)$ [2]

Diberikan matriks $A \in M_{m x n}(R)$

a. $0 \leq r k(A) \leq \min \{m, n\}$

b. Untuk $m=n, r k(A)<n$ jika hanya jika $\operatorname{det}(A) \in Z(R), \quad$ dimana $\quad Z(R) \quad$ adalah himpunan semua pembagi nol di $R$.

\section{Bukti:}

a. Berdasarkan Akibat Teorema 3.1. jelas bahwa $I_{0}(A)=R$, sehingga menurut Definisi 2.18. tentang annihilator diperoleh $A n n_{R}\left(I_{0}(A)\right)=A n n_{R}(R)=0$. 
Berdasarkan Definisi 2.19 tentang rank matriks diperoleh $r k(A) \geq 0$. Di sisi lain, untuk $A \in M_{m x n}(R)$ dengant $>\min \{m, n\}$ ditunjukkan bahwa $r k(A) \neq t$. Menurut Akibat Teorema 3.1. diperoleh bahwa $I_{t}(A)=0$. Karena untuk $t>\min \{m, n\}$ diperoleh $I_{t}(A)=0$, menurut Definisi 2.18. diperoleh bahwa $\quad \operatorname{Ann}_{R}\left(I_{t}(A)\right)=$ $\operatorname{Ann}_{R}(0)=R$. Jelas bahwa untuk $t>$ $\min \{m, n\}, \quad$ diperoleh bahwa $\operatorname{Ann}_{R}\left(I_{t}(A)\right) \neq 0, \quad$ sehingga menurut Definisi 2.19. $r k(A) \neq t$. Karena telah dibuktikan untuk $A \in M_{m x n}(R)$ dimanat $>$ $\min \{m, n\}$ maka $r k(A) \neq t$. Jelas terbukti bahwa untuk $A \in M_{m \times n}(R)$ berlaku jika $r k(A)=t$ maka $t \leq \min \{m, n\}$. Karena untuk $A \in M_{m x n}(R)$ berlaku $r k(A) \geq 0$ dan $r k(A) \leq \min \{m, n\} \quad$ maka $0 \leq r k(A) \leq$ $\min \{m, n\}$.

b. Harus ditunjukkan bahwa untuk $m=n$, jika $r k(A)<n$ maka $\operatorname{det}(A) \in Z(R)$ dan jika $(A) \in Z(R)$ maka $r k(A)<n$

Pertama, ditunjukkan bahwa untuk $m=n$, jika $r k(A)<n$ maka $\operatorname{det}(A) \in Z(R)$. Diketahui untuk $A \in M_{m x n}(R)$ dengan $r k(A)<n$. Karena $r k(A)<n$, menurut Definisi 2.19. $A n n_{R}\left(I_{n}(A)\right) \neq 0$. Karena $A n n_{R}\left(I_{n}(A)\right) \neq 0$, menurut Definisi 2.18. terdapat $\quad x \in R-\{0\}=R^{*} \quad$ sedemikian sehingga $x a=0$, dimana $a$ adalah anggota $I_{n}(A)$. Menurut Definisi 2.8. a adalah pembagi nol di $R$ atau dapat ditulis $a \in$ $Z(R)$. Karena $a$ adalah anggota $I_{n}(A)$, menurut Definisi 2.17. $a=\operatorname{det}(A) \in I_{n}(A)$. Dengan kata lain, $\operatorname{det}(A) \in Z(R)$.

Kedua, ditunjukkan untuk $m=n$, jika $\operatorname{det}(A) \in Z(R)$ maka $r k(A)<n$. Diketahui $\operatorname{det}(A) \in Z(R)$, menurut Definisi 2.8 . $\operatorname{det}(A)$ adalah suatu pembagi nol di $R$. Misalkan $a=\operatorname{det}(A) \in Z(R)$, menurut Definisi 2.8. terdapat $x \in R^{*}=R-\{0\}$ sedemikian sehingga $a x=0$. Untuk $m=n$, $a=\operatorname{det}(A) \in I_{n}(A), \quad$ sehingga menurut Definisi 2.18. diperoleh $\operatorname{Ann}_{R}\left(I_{n}(A)=x\right.$ atau $\operatorname{Ann}_{R}\left(I_{n}(A)\right) \neq 0$, untuk $x \in R^{*}$. Karena $\operatorname{Ann}_{R}\left(I_{n}(A)\right) \neq 0$, menurut Definisi 2.19. $r k(A) \neq n$. Diperoleh $r k(A) \neq n$ dan berdasarkan Teorema 3.2.a. diketahui bahwa $0 \leq r k(A) \leq \min \{m, n\}$. Karena untuk $m=n, r k(A) \neq n \quad$ dan $\quad 0 \leq r k(A) \leq$ $\min \{m, n\}$, dapat disimpulkan bahwa $r k(A)<n$.

Diperoleh untuk $m=n$, berlaku jika $r k(A)<n$ maka $\operatorname{det}(A) \in Z(R)$ dan jika $(A) \in$ $Z(R)$ maka $r k(A)<n$. Dengan kata lain, terbukti bahwa untuk $m=n, r k(A)<n$ jika hanya jika $\operatorname{det}(A) \in Z(R)$.

\section{Akibat Teorema 3.2.}

Untuk $m=n, \quad r k(A)=n$ jika hanya jika $\operatorname{det}(A) \notin Z(R)$, dengan $Z(R)$ adalah himpunan semua pembagi nol di $R$.

\section{Bukti:}

Harus ditunjukkan bahwa $m=n$, jika $r k(A)=$ $n$ maka $\operatorname{det}(A) \notin Z(R)$, dan jika $\operatorname{det}(A) \notin$ $Z(R)$ maka $r k(A)=n$, dimana $Z(R)$ adalah himpunan semua pembagi nol di $R$

Pertama, ditunjukkan bahwa untuk $m=$ $n$ berlaku jika $\operatorname{det}(A) \notin Z(R)$ maka $r k(A)=$ $n$. Berdasarkan Teorema 3.2. diketahui bahwa untuk $m=n$ berlaku jika $r k(A)<n$ maka $\operatorname{det}(A) \in Z(R)$. Hal ini menyebabkan untuk $m=n$ juga berlaku jika $\operatorname{det}(A) \notin Z(R)$ maka $r k(A) \geq n$. Berdasarkan Teorema 3.1.a, untuk $m=n \quad$ berrlaku $\quad 0 \leq r k(A) \leq$ $\min \{n, n\}=n$. Karena untuk $m=n$ berlaku $0 \leq r k(A) \leq n$ dan disisi lain $r k(A) \geq n$, maka $r k(A)=n$. Sehingga untuk $m=n$ berlaku jika $\operatorname{det}(A) \notin Z(R)$ maka $r k(A)=n$.

Kedua, ditunjukkan bahwa untuk $m=n$ berlaku jika $r k(A)=n$ maka $\operatorname{det}(A) \notin Z(R)$. Diketahui bahwa jika untuk $m=n$, jika $\operatorname{det}(A) \in Z(R)$ maka $r k(A)<n$. Hal ini juga menyebakan bahwa untuk $m=n$ berlaku jika $r k(A) \geq n$ maka $\operatorname{det}(A) \notin Z(R)$. Menurut Teorema 3.1.a, $0 \leq r k(A) \leq \min \{n, n\}=n$. Karena diketahui bahwa $r k(A) \geq n$ dan $0 \leq$ $r k(A) \leq n$, dapat disimpulkan bahwark $(A)=$ $n$. Berarti terbukti bahwa untuk $m=n$ berlaku jika $r k(A)=n$ maka $\operatorname{det}(A) \notin Z(R)$. 
Contoh:

a. Diketahui ring komutatif $R=Z_{6}=$ $\{\overline{0}, \overline{1}, \overline{2}, \overline{3}, \overline{4}, \overline{5}\}$ dan matriks

$$
P=\left[\begin{array}{lll}
\overline{1} & \overline{2} & \overline{3} \\
\overline{0} & \overline{4} & \overline{5}
\end{array}\right] \in M_{2 \times 3}(R)
$$

Ditentukan $r k(P)$. Untuk menentukan $r k(P)$, menurut Definisi 2.19, terlebih ditentukan semua annihilator dari ideal-ideal matriks $P$ yang sama dengan $\overline{0}$. Selanjutnya, ditentukan nilai maksimum $t \in Z$ dimana annihilator dari ideal-ideal matriks $P$ yang sama dengan $\overline{0}$. Ambil semua submatriks 1 x 1 dari $P$ yaitu $[\overline{0}],[\overline{1}],[\overline{2}],[\overline{3}],[\overline{4}],[\overline{5}]$ dan submatriks $2 \mathrm{x}$ 2 dari $P$ yaitu $\left[\begin{array}{ll}\overline{1} & \overline{2} \\ \overline{0} & \overline{4}\end{array}\right],\left[\begin{array}{ll}\overline{1} & \overline{3} \\ \overline{0} & \overline{5}\end{array}\right],\left[\begin{array}{ll}\overline{2} & \overline{3} \\ \overline{4} & \overline{5}\end{array}\right]$. Menurut Definisi 2.14. minor dari submatriks-submatriks tersebut yaitu $\Delta(1 ; 1)=|\overline{1}|=\overline{1}, \quad \Delta(1 ; 2)=|\overline{2}|=\overline{2}$, $\Delta(1 ; 3)=|\overline{3}|=\overline{3}, \quad \Delta(2 ; 1)=|\overline{0}|=\overline{0}$, $\Delta(2 ; 2)=|\overline{4}|=\overline{4}, \quad \Delta(2 ; 3)=|\overline{5}|=\overline{5}$, $\Delta(1,2 ; 1,2)=\left|\begin{array}{ll}\overline{1} & \overline{2} \\ \overline{0} & \overline{4}\end{array}\right|=\overline{4}, \quad \Delta(1,2 ; 1,3)=$ $\left|\begin{array}{ll}\overline{1} & \overline{3} \\ \overline{0} & \overline{5}\end{array}\right|=\overline{5}$ dan $\Delta(1,2 ; 2,3)=\left|\begin{array}{ll}\overline{2} & \overline{3} \\ \overline{4} & \overline{5}\end{array}\right|=\overline{2}$. Berdasarkan minor masing-masing submatriks, ditentukan $I_{1}(P)$ dan $I_{2}(P)$, menurut Definisi 2.17. diperoleh bahwa

$$
\begin{aligned}
I_{1}(P) & =\overline{0} R+\overline{1} R+\overline{2} R+\overline{3} R+\overline{4} R+\overline{5} R=R \\
I_{2}(P) & =\overline{2} R+\overline{4} R+\overline{5} R=R
\end{aligned}
$$

Selain itu, menurut Akibat Teorema 3.1. untuk $t \in Z$ berlaku $I_{t}(P)=R$ untuk $t \leq 0$ dan $I_{t}(P)=\overline{0}$ untuk $t>2$. Berdasarkan ideal yang terbentuk, ditentukan annihilator masing-masing ideal, menurut Definisi 2.18. diperoleh

$$
\begin{aligned}
& \operatorname{Ann}_{R}\left(I_{1}(P)\right)=A n_{R}(R)=\overline{0} \\
& A_{A n n_{R}}\left(I_{2}(P)\right)=A_{R}(R)=\overline{0} \\
& A_{R}\left(I_{t}(P)\right)=A_{R}(R)=\overline{0}, \text { untuk } t \leq 0 \\
& A_{R}\left(I_{t}(P)\right)=A_{R}(\overline{0})=R, \text { untuk } t>2
\end{aligned}
$$

Berdasarkan annihilator, ditentukan $r k(P)$ yang menurut Definisi 2.19 diperoleh

$$
r k(A)=\operatorname{maks}\left\{t \mid A n n_{R}\left(I_{t}(A)\right)=(0)\right\}
$$

$$
=\operatorname{maks}\{t \in Z \mid t \leq 2\}
$$$$
=2
$$

Diperoleh $r k(A)=2=\min \{2,3\}$. Hal ini sesuai dengan Teorema 3.2.a.

b. Diberikan $R=Z_{6}=\{\overline{0}, \overline{1}, \overline{2}, \overline{3}, \overline{4}, \overline{5}\}$. Ambil matriks

$$
\begin{aligned}
A & =\left[\begin{array}{ll}
\overline{2} & \overline{2} \\
\overline{0} & \overline{2}
\end{array}\right] \in M_{2 \times 2}(R), \\
B & =\left[\begin{array}{ll}
\overline{2} & 0 \\
\overline{0} & \overline{3}
\end{array}\right] \in M_{2 \times 2}(R), \\
C & =\left[\begin{array}{ll}
\overline{1} & \overline{3} \\
\overline{0} & \overline{5}
\end{array}\right] \in M_{2 \times 2}(R) \mathrm{dan} \\
D & =\left[\begin{array}{ll}
\overline{1} & \overline{0} \\
\overline{3} & \overline{1}
\end{array}\right] \in M_{2 \times 2}(R) .
\end{aligned}
$$

Ditentukan $r k(A), r k(B), r k(C)$ dan $r k(D)$ Untuk matriks $A$, diperoleh $|A|=\left|\begin{array}{ll}\overline{2} & \overline{2} \\ \overline{0} & \overline{2}\end{array}\right|=$ $\overline{4} \in Z(R)$. Berdasarkan Definisi 2.19. untuk menentukan $r k(A)$, ambil semua anggota $I_{1}(A)$ dan $I_{2}(A)$, beserta annihilatornya masing-masing. Berdasarkan Definisi 2.17. diperoleh

$$
\begin{aligned}
& I_{1}(A)=\overline{2} R=\{\overline{0}, \overline{2}, \overline{4}\} \\
& I_{2}(A)=\overline{4} R=\{\overline{0}, \overline{2}, \overline{4}\}
\end{aligned}
$$

Sehingga diperoleh $I_{1}(A)=I_{2}(A)=$ $\{\overline{0}, \overline{2}, \overline{4}\}$. Berdasarkan Definisi 2.18 . annihilator dari $I_{1}(A)$ dan $I_{2}(A)$ adalah

$$
\begin{aligned}
& \operatorname{Ann}_{R}(\overline{0})=R \\
& \operatorname{Ann}_{R}(\overline{2})=\{\overline{0}, \overline{3}\}=\overline{3} R \\
& \operatorname{Ann}_{R}(\overline{4})=\{\overline{0}, \overline{3}\}=\overline{3} R
\end{aligned}
$$

Sehingga diperoleh $A n n_{R}\left(I_{1}(A)\right)=$ $\operatorname{Ann}_{R}\left(I_{2}(A)\right)=\overline{3} R$

Diperoleh $A n n_{R}\left(I_{1}(A)\right)=A n n_{R}\left(I_{2}(A)\right)=$ $\overline{3} R \neq \overline{0}$, tetapi menurut Akibat Teorema 3.1. untuk $t \leq 0$ berlaku $I_{t}(A)=R$, sehingga menurut Definisi 2.18. $\operatorname{Ann}_{R}\left(I_{t}(A)\right)=0$, untuk $t \leq 0, t \in Z$. Berdasarkan Definisi 2.19. diperoleh

$$
\begin{aligned}
r k(A) & =\operatorname{maks}\left\{t \mid \operatorname{Ann}_{R}\left(I_{t}(A)\right)=(0)\right\} \\
& =\operatorname{maks}\{t \in Z \mid t \leq 0\} \\
& =0
\end{aligned}
$$

Sehingga diperoleh $r k(A)=0<2$ dengan $\operatorname{det}(A)=\overline{4} \in Z(R)$. Hal ini sesuai dengan Teorema 3.2.b.

Untuk matriks $B$, diperoleh $|B|=\left|\begin{array}{ll}\overline{2} & \overline{0} \\ \overline{0} & \overline{3}\end{array}\right|=$ $\overline{0} \in Z(R)$. Berdasarkan Definisi 2.19. untuk 
menentukan $r k(B)$, ambil semua anggota $I_{1}(B)$ dan $I_{2}(B)$, beserta annihilatornya masing-masing. Berdasarkan Definisi 2.17. diperoleh

$$
\begin{aligned}
& I_{1}(B)=\overline{2} R+\overline{3} R=R \\
& I_{2}(B)=0
\end{aligned}
$$

dan menurut Akibat Teorema 3.1. $I_{t}(B)=$ $R$, untuk $t \in Z$ dan $t \leq 0$. Menurut Definisi 2.18. annihilator $I_{1}(B)$ dan $I_{2}(B)$ yaitu

$$
\begin{aligned}
& A n n_{R}\left(I_{1}(B)\right)=A_{R}(R)=\overline{0} \\
& A_{R}\left(I_{2}(B)\right)=A n n_{R}(\overline{0})=R
\end{aligned}
$$

Sedangkan untuk $t \in Z$ dan $t \leq 0$, $\operatorname{Ann}_{R}\left(I_{t}(A)\right)=0$. Berdasarkan Definisi 2.19. diperoleh

$$
\begin{aligned}
r k(B) & =\operatorname{maks}\left\{t \mid \operatorname{Ann}_{R}\left(I_{t}(B)\right)=(0)\right\} \\
& =\operatorname{maks}\{t \in Z \mid t \leq 1\} \\
& =1
\end{aligned}
$$

Sehingga diperoleh $r k(B)=1<2$ dengan $\operatorname{det}(A)=\overline{0} \in Z(R)$. Hal ini sesuai dengan Teorema 3.2.b.

Untuk matriks $C$, diperoleh $|C|=\left|\begin{array}{ll}\overline{1} & \overline{3} \\ \overline{0} & \overline{5}\end{array}\right|=$ $\overline{5}$. Berdasarkan Definisi 2.19. untuk menentukan $r k(C)$, ambil semua anggota $I_{1}(C)$ dan $I_{2}(C)$, beserta annihilatornya masing-masing. Berdasarkan Definisi 2.17. diperoleh

$$
\begin{aligned}
& I_{1}(C)=\overline{0} R+\overline{1} R+\overline{3} R+\overline{5} R=R \\
& I_{2}(C)=\overline{5} R=R
\end{aligned}
$$

dan menurut Akibat Teorema 3.1. $I_{t}(C)=$ $R$, untuk $t \in Z$ dan $t \leq 0$. Menurut Definisi 2.18. annihilator $I_{1}(C)$ dan $I_{2}(C)$ yaitu

$$
\begin{aligned}
& \operatorname{Ann}_{R}\left(I_{1}(C)\right)=\operatorname{Ann}_{R}(R)=\overline{0} \\
& \operatorname{Ann}_{R}\left(I_{2}(C)\right)=\operatorname{Ann}_{R}(R)=\overline{0}
\end{aligned}
$$

Sedangkan untuk $t \in Z$ dan $t \leq 0$, $\operatorname{Ann}_{R}\left(I_{t}(A)\right)=0$. Berdasarkan Definisi 2.19. diperoleh

$$
\begin{aligned}
r k(C) & =\operatorname{maks}\left\{t \mid \operatorname{Ann}_{R}\left(I_{t}(C)\right)=(0)\right\} \\
& =\operatorname{maks}\{t \in Z \mid t \leq 2\} \\
& =2
\end{aligned}
$$

Sehingga diperoleh $r k(C)=2$ dengan $\operatorname{det}(A)=\overline{5} \notin Z(R)$. Hal ini sesuai dengan Akibat Teorema 3.2.

Untuk matriks $D$, diperoleh $|D|=\left|\begin{array}{ll}\overline{1} & \overline{0} \\ \overline{3} & \overline{1}\end{array}\right|=$ $\overline{1} \in U(R)$. Berdasarkan Definisi 2.19. untuk menentukan $r k(D)$, ambil semua anggota
$I_{1}(D)$ dan $I_{2}(D)$, beserta annihilatornya masing-masing. Berdasarkan Definisi 2.17. diperoleh

$$
\begin{aligned}
& I_{1}(D)=\overline{0} R+\overline{1} R+\overline{3} R=R \\
& I_{2}(D)=\overline{1} R=R
\end{aligned}
$$

dan menurut Akibat Teorema 3.1. $I_{t}(D)=$ $R$, untuk $t \in Z$ dan $t \leq 0$. Menurut Definisi 2.18. annihilator $I_{1}(D)$ dan $I_{2}(D)$ yaitu

$$
\begin{aligned}
& A n n_{R}\left(I_{1}(D) ;=A^{\prime} n_{R}(R)=\overline{0}\right. \\
& A n n_{R}\left(I_{2}(D) ;=A n n_{R}(R)=\overline{0}\right.
\end{aligned}
$$

Sedangkan untuk $t \in Z$ dan $t \leq 0$, $\operatorname{Ann}_{R}\left(I_{t}(D)\right)=0$. Berdasarkan Definisi 2.19. diperoleh

$$
\begin{aligned}
r k(D) & =\operatorname{maks}\left\{t \mid \operatorname{Ann}_{R}\left(I_{t}(D)\right)=(0)\right\} \\
& =\operatorname{maks}\{t \in Z \mid t \leq 2\} \\
& =2
\end{aligned}
$$

Sehingga diperoleh $r k(D)=2$ dengan $\operatorname{det}(A)=\overline{1} \in U(R) \notin Z(R)$. Hal ini sesuai dengan Akibat Teorema 3.2.

\section{Kesimpulan}

Berdasarkan pembahasan di atas, dapat disimpulkan bahwa rank matriks atas ring komutatif yang berukuran $n \times n$ lebih kecil dari $n$, jika determinan matriks tersebut merupakan anggota pembagi nol di ring komutatif. Begitu juga, rank matriks atas ring komutatif yang berukuran $n \times n$ sama dengan $n$, jika determinan matriks tersebut bukan anggota pembagi nol di ring komutatif.

\section{Referensi}

[1] Bhattacharya, P.B., Jain, S.K., \&Nagpaul, S.R., Basic Abstract Algebra, Press Sydicate, Australia (1990).

[2] Brown, W.C., Matrices over Commutative Rings, Marcel Dekker Inc, New York (1993).

[3] Durbin, J.R., Modern Algebra An Introduction, John Willey and Sons Inc. New York (1992).

[4] Leon, S.J., Aljabar Linier dan Aplikasinya, Erlangga, Jakarta (2001). 